\title{
Analisis Strategi Bisnis Pada Pt. Galleon Cahaya Investama Untuk Meningkatkan Daya Saing Dalam Persaingan Di Pasar
}

\author{
Yakobus Luke \\ Program Studi Magister Manajemen Universitas Tarumanagara \\ yakobluke2@gmail.com
}

\begin{abstract}
This study is to analyze and formulate the best strategy for PT. Galleon Cahaya Investama. This study uses IFE, EFE, SWOT, IE Matrix and QSPM Matrix to obtain the best result for the company. Source of data derived from observations, questionnaires and interviews with the related parties of the company, literature studies and related additional data. The usage of IFE Matrix and EFE Matrix is to analyze the internal and external factors of PT. Galleon Cahaya Investama. Trough these methods, the analysis applied for strength, weaknesses, opportunities and threats. While SWOT analysis will give the wide range of alternative strategies that can be used by PT. Galleon Cahaya Investama. IE Matrix will give us the position of company's condition. The analysis obtained from the input stage and matching stage would be combined and analyzed through a further process to get the best strategy by using QSPM Matrix. The conclusion of this study is market development strategy because PT. Galleon Cahaya Investama has sufficient strength and must take the advantage of existing opportunities. Furthermore there are so many development and customer needs that must be fulfilled. To excel in such competition, PT. Galleon Cahaya Investama has to use their human resources skill in order to increase customer satisfaction.
\end{abstract}

Abstrak: Penelitian ini dilakukan untuk menganalisa dan menyusun strategi terbaik untuk PT. Galleon Cahaya Investama. Penelitan ini menggunakan, IFE, EFE, SWOT, IE dan QSPM untuk mendapatkan hasil terbaik bagi PT. Galleon Cahaya Investama. Sumber data didapat dari observasi, kuisioner dan wawancara kepada pihak terkait dari perusahaan, studi literatur dan data tambahan terkait. Penggunaan matriks IFE dan EFE yaitu untuk menganalisa faktorfaktor internal dan eksternal dari PT. Galleon Cahaya Investama. Melalui metode ini, analisa dilakukan pada kekuatan, kelemahan, peluang dan ancaman. Analisa SWOT akan memberikan strategi alternative yang dapat digunakan oleh PT. Galleon Cahaya Investama. Matriks IE akan menunjukkan posisi dari kondisi perusahaan. Analisa yang didapat dari tahapan pemasukan dan pencocokan akan digabungkan dan dianalisa melalui proses yang lebih jauh dengan QSPM. Konklusi dari penelitian ini adalah penggunaan strategi pengembangan pasar karena perusahaan memiliki kekuatan yang lebih dan harus memanfaatkan peluang yang ada. Lebih jauh lagi ada pengembangan dan kebutuhan pelanggan yang harus dipenuhi. Untuk unggul dalam persaingan, perusahaan harus menggunakan kemampuan sumber daya manusia mereka untuk meningkatkan kepuasan konsumen.

Keywords: IFE, EFE, IE Matrix, SWOT Matrix, QSPM Matrix

\section{PENDAHULUAN}

Pertumbuhan perekonomian di Indonesia telah membawa dampak yang sangat tinggi terhadap masyarakat. Menurut Bank Dunia pertumbuhan perekonomian Indonesia terus berkembang dengan tinggi pada kuartal pertama tahun 2018 dan didorong oleh kuatnya investasi (Chaves et al., 2018). Hal ini terlihat dari banyaknya perusahaan yang muncul. Industri listrik dimana PT. Galleon Cahaya Investama bernaung merupakan industri yang semakin ramai sehingga perlu adanya strategi perusahaan yang tepat agar perusahaan dapat bertahan, sementara perusahaan ini merupakan perusahaan yang belum besar dan bahkan 
masih berusia muda. Penentuan strategi merupakan alat yang efektif dalam menghadapi tantangan dan persaingan (Koupaei et al., 2015). Tanpa adanya strategi yang tepat akan membuat perusahaan sulit untuk berkembang dan bertahan dalam persaingan. Penggunaan matriks strategi akan membantu perusahaan dalam mengevaluasi dan mengembangkan strategi yang membawa perusahaan mengalami titik balik ke arah yang lebih baik (Lu, 2017).

Penggunaan matriks strategi memerlukan analisa faktor internal dan eksternal pada perusahaan. Mehbodi et al. (2018) menyatakan bahwa untuk mengevaluasi faktor eksternal dan internal tersebut dapat digunakan EFE (External Factor Evaluation) matrix dan IFE (Internal Factor Evaluation) matrix. Hasil dari analisa melalui kedua matriks tersebut akan dipakai dalam analisa SWOT (Strength, Weakness, Opportunities, Threat). Sementara untuk mengetahui posisi perusahaan dengan strategi yang kira-kira sesuai akan digunakan analisa melalui Internal External Matrix (IE Matrix).

Selanjutnya Satpayeva (2017) menyatakan bahwa alternatif strategi yang didapatkan dari analisa SWOT dan matriks IE akan dievaluasi dan dipilih strategi yang paling tepat melalui matriks QSPM (Quantitative Strategic Planning Matrix). Melalui matriks strategi ini perusahaan dapat mengetahui langkah yang harus diambil untuk bertahan dalam persaingan bisnis.

Tujuan dilakukannya penelitian ini yaitu untuk menganalisa lingkungan eksternal perusahaan untuk mendapatkan peluang dan ancaman yang dihadapi, serta kekuatan dan kelemahan yang dimiliki oleh perusahaan dan Untuk mengetahui faktor-faktor yang perlu ditingkatkan agar dapat meningkatkan daya saing PT. Galleon Cahaya Investama dalam bersaing dengan para kompetitornya.

Berdasarkan latar belakang yang dikemukakan terdahulu, maka judul penelitian ini adalah "Analisis Strategi Bisnis Pada PT. Galleon Cahaya Investama untuk Meningkatkan Daya Saing dalam Persaingan di Pasar". Telaah Kepustakaan

Matriks yang digunakan dalam penelitian ini merupakan alat yang dapat diandalkan karena sering digunakan oleh peneliti untuk strategi perusahaan. Matriks IFE, EFE, SWOT, IE dan QSPM digunakan untuk mengevaluasi dan mengembangkan strategi perusahaan yang diteliti (Lu, 2017).

- Pengertian Manajemen Strategik

Menurut Pearce dan Robinson (2016) manajemen strategis adalah suatu rangkaian keputusan dan tindakan yang menghasilkan formulasi dan implementasi rencana untuk mencapai tujuan perusahaan.

- Matriks IFE

Internal Factor Evaluation Matrix (IFE Matrix) merupakan suatu alat yang digunakan untuk menganalisa faktor-faktor internal dari perusahaan yang mencakup kekuatan (strength) dan kelemahan (weakness) yang ada. Analisa internal fokus pada kekuatan dan kelemahan perusahaan yang akan berpengaruh pada persaingan yang dihadapi perusahaan (Neelesh \& Kushwah, 2018).

- Matriks EFE

External Factor Evaluation Matrix (EFE Matrix) merupakan suatu alat yang membantu untuk menganalisa faktor-faktor eksternal dari industri perusahaan yang terkait. Friedrichsen et al. (2017) menyatakan bahwa Internal Factor Evaluation Matrix (IFE Matrix) menganalisa tentang kekuatan dan kelemahan yang dimiliki oleh suatu perusahaan.

- Analisa SWOT

Hossain et al. (2017) menjelaskan analisa SWOT adalah perencanaan terstruktur, metode yang digunakan untuk mengevaluasi kekuatan, kelemahan, peluang dan ancaman dalam suatu bisnis atau industri. 
- Matriks IE

Untuk dapat mengetahui posisi perusahaan dan alternatif yang dapat diaplikasikan maka dapat digunakan Internal External Matrix (IE Matrix).

- Matriks QSPM

Quantitative Strategic Planning Matrix (QSPM) merupakan matriks yang dalam memilih strategi alternatif mana yang paling baik. Melalui matriks QSPM berbagai strategi alternatif yang ada dapat dievaluasi sehingga akan didapat strategi yang menjadi solusi bagi perusahaan (Pazouki et al., 2017).

\section{METODE PENELITIAN}

Dalam penelitian ini jenis metode yang digunakan adalah metode kualitatif. Penelitian ini bersifat deskriptif yaitu melalui penelitian ini dapat diberikan suatu gambaran atau uraian keadaan secara faktual dan jelas. Penelitian ini menggunakan data primer yakni data mengenai faktor-faktor internal dan eksternal perusahaan didapatkan melalui kuisioner yang dibagikan kepada responden yakni pihak manajemen perusahaan PT. Galleon Cahaya Investama. Kuisioner dibagikan kepada manajemen atas yang terdiri dari delapan orang manajemen atas dan dilakukan diskusi dengan pihak manajemen mengenai setiap faktor yang digunakan. Selain itu penelitian ini juga menggunakan data sekunder yang menggunakan buku-buku mengenai manajemen stratejik, jurnal, pencarian melalui internet serta sumber lainnya yang digunakan untuk menyiapkan penelitian ini.

\section{- Matriks IFE}

Dari hasil penelitian didapatkan bahwa nilai total bernilai 2,80, dimana hasil tersebut berada diatas nilai rata-rata yakni 2,5. Dari nilai tersebut dapat diketahui bahwa perusahaan memiliki ketahanan untuk menghadapi dunia industri serta mampu untuk dapat mengatasi kelemahan yang dimiliki.

- Matriks EFE

Dari hasil analisa matriks EFE didapatkan hasil jumlah total sebesar 3,05. Hasil yang didapat ini berada diatas rata-rata yakni 2,5. Dapat dilihat dari hasil yang didapat diatas bahwa perusahaan dapat merespon dengan baik peluang serta ancaman yang ada didalam industri terkait.

\section{- Analisa SWOT}

\begin{tabular}{|c|c|c|}
\hline & $\begin{array}{l}\text { Kekuatan (Strength) } \\
\text { 1.Perusahaan cukup } \\
\text { dikenal oleh kalangan } \\
\text { masyarakat } \\
\text { 2.Menyediakan peralatan } \\
\text { engineering yang lengkap } \\
\text { 3.Mampu memberikan } \\
\text { layanan kepada pelanggan } \\
\text { dengan cepat } \\
\text { 4.Teknisi yang ahli dalam } \\
\text { menangani peralatan } \\
\text { engineering } \\
\text { 5.Harga barang yang } \\
\text { ditawarkan terjangkau }\end{array}$ & $\begin{array}{l}\text { Kelemahan } \\
\text { (Weakness) } \\
\text { 1. Proses administrasi } \\
\text { transaksi barang yang } \\
\text { rumit } \\
\text { 2. Layanan purna jual } \\
\text { yang kurang baik } \\
\text { 3. Barang yang dipesan } \\
\text { sering tidak ada stok } \\
\text { dan indent } \\
\text { 4. Lokasi perusahaan } \\
\text { kurang dapat dijangkau } \\
\text { 5. Barang yang dijual } \\
\text { kurang berkualitas }\end{array}$ \\
\hline $\begin{array}{l}\text { Peluang(Opportunities) } \\
\text { 1.Meningkatnya } \\
\text { permintaan kebutuhan } \\
\text { engineering }\end{array}$ & $\begin{array}{l}\text { S-O (Strength- } \\
\text { Opportunities) } \\
\text { 1. Memperbanyak } \\
\text { pemasaran barang (S1,S2- } \\
\text { O1,O3) }\end{array}$ & $\begin{array}{l}\text { W-O (Weakness- } \\
\text { Opportunities) } \\
\text { 1. Membuka layanan } \\
\text { online }(\mathrm{W} 2, \mathrm{~W} 4-\mathrm{O} 2)\end{array}$ \\
\hline
\end{tabular}




\begin{tabular}{|c|c|c|}
\hline $\begin{array}{l}\text { 2.Meningkatnya } \\
\text { pembangunan di daerah } \\
\text { Jabodetabek } \\
\text { 3.Banyaknya perawatan } \\
\text { untuk pembangkit tenaga } \\
\text { listrik } \\
\text { 4.Banyaknya rekomendasi } \\
\text { yang diberikan pelanggan } \\
\text { 5.Dukungan pemerintah } \\
\text { untuk usaha lokal }\end{array}$ & $\begin{array}{l}\text { 2. Memperbanyak teknisi } \\
\text { (S3-O2) } \\
\text { 3. Membuka cabang di } \\
\text { daerah }(\mathrm{S} 5-\mathrm{O} 4, \mathrm{O} 5)\end{array}$ & $\begin{array}{l}\text { 2. Memperbanyak } \\
\text { jaringan pemasok (W3- } \\
\text { O3) } \\
\text { 3. Membuat SOP baru } \\
(\mathrm{W} 1-\mathrm{O} 1, \mathrm{O} 4)\end{array}$ \\
\hline $\begin{array}{l}\text { Ancaman (Threat) } \\
\text { 1.Banyaknya perusahaan } \\
\text { yang juga menjual barang } \\
\text { yang sama } \\
\text { 2.Banyak pelanggan yang } \\
\text { beralih ke barang substitusi } \\
\text { 3.Terdapat tingkat } \\
\text { kemacetan yang } \\
\text { mengganggu distribusi } \\
\text { barang } \\
\text { 4.Terdapat tren } \\
\text { penggunaan peralatan } \\
\text { ramah lingkungan } \\
\text { 5.Terdapat batasan produk } \\
\text { listrik impor oleh } \\
\text { pemerintah }\end{array}$ & $\begin{array}{l}\text { S-T (Strength-Threat) } \\
\text { 1. Mengembangkan tim } \\
\text { R\&D untuk produk } \\
\text { inovasi(S2-T1,T4) } \\
\text { 2. Memberikan } \\
\text { pendidikan khusus teknik } \\
\text { (S4-T5) } \\
\text { 3. Memperbanyak } \\
\text { transportasi untuk } \\
\text { distribusi barang (S3-T3) }\end{array}$ & $\begin{array}{l}\text { W-T (Weakness- } \\
\text { Threat) } \\
\text { 1. Mengadakan } \\
\text { pelatihan layanan purna } \\
\text { jual (W2-T1) } \\
\text { 2. Menaikkan standar } \\
\text { kualitas produk (W5- } \\
\text { T2, T4) } \\
\text { 3. Penggunaan } \\
\text { pemasok lokal (W3- } \\
\text { T5) }\end{array}$ \\
\hline
\end{tabular}

- Matriks IE

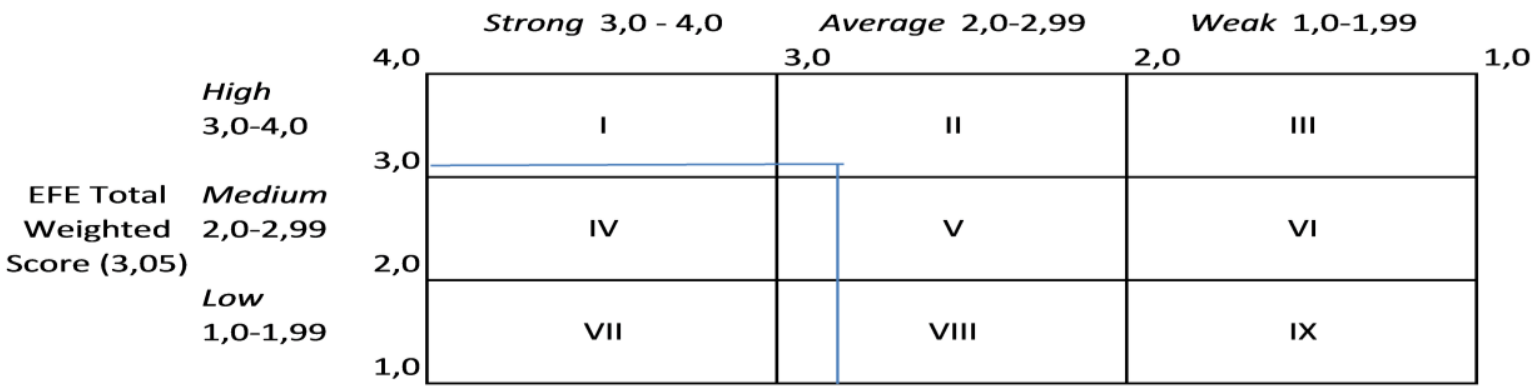

IFE Total Weighted Score $(2,80)$ 
- QSPM

\begin{tabular}{|l|c|c|c|c|c|}
\hline \multicolumn{2}{|c|}{ Alternatif Strategi } & \multicolumn{2}{c|}{$\begin{array}{c}\text { Pengembangan } \\
\text { pasar }\end{array}$} & \multicolumn{2}{c|}{$\begin{array}{c}\text { Pengembangan } \\
\text { Produk }\end{array}$} \\
\hline \multicolumn{1}{|c|}{ Fakr-Faktor } & Bobot & AS & TAS & AS & TAS \\
\hline Peluang (Opportunities) & & & & & \\
\hline Meningkatnya permintaan kebutuhan engineering & 0.08 & 4 & 0,32 & 4 & 0,32 \\
\hline Meningkatnya pembangunan di daerah Jabodetabek & 0,12 & 4 & 0,48 & 4 & 0,48 \\
\hline Banyaknya perawatan untuk pembangkit tenaga listrik & 0,09 & 3 & 0,27 & 3 & 0,27 \\
\hline Banyaknya rekomendasi yang diberikan pelanggan & 0,13 & 3 & 0,39 & 2 & 0,26 \\
\hline Dukungan pemerintah untuk usaha lokal & 0,07 & 3 & 0,21 & 3 & 0,21 \\
\hline Ancaman (Threat) & & & & & \\
\hline Banyaknya perusahaan yang juga menjual barang yang sama & 0,17 & 2 & 0,34 & 4 & 0,68 \\
\hline Banyak pelanggan yang beralih ke barang substitusi & 0,08 & 3 & 0,24 & 4 & 0,32 \\
\hline Terdapat tingkat kemacetan yang mengganggu distribusi barang & 0,09 & - & & - & \\
\hline Terdapat tren penggunaan peralatan ramah lingkungan & 0,10 & 3 & 0,30 & 4 & 0,40 \\
\hline Terdapat batasan produk listrik impor oleh pemerintah & 0,07 & 3 & 0,21 & 3 & 0,21 \\
\hline Kekuatan (Strength) & & & & & \\
\hline Perusahaan cukup dikenal oleh kalangan masyarakat & 0,10 & 4 & 0,4 & 2 & 0,2 \\
\hline Menyediakan peralatan engineering yang lengkap & 0,13 & 4 & 0,52 & 4 & 0,52 \\
\hline Mampu memberikan layanan kepada pelanggan dengan cepat & 0,14 & 4 & 0,56 & 1 & 0,14 \\
\hline Teknisi yang ahli dalam menangani peralatan engineering & 0,20 & 3 & 0,6 & 1 & 0,2 \\
\hline Harga barang yang ditawarkan terjangkau & 0,12 & 4 & 0,48 & 3 & 0,36 \\
\hline Kelemahan (Weakness) & & & & & \\
\hline Proses administrasi transaksi barang yang rumit & 0,12 & 2 & 0,24 & 1 & 0,12 \\
\hline Layanan purna jual yang kurang baik & 0,05 & 3 & 0,15 & 2 & 0,1 \\
\hline Barang yang dipesan sering tidak ada stok dan indent & 0,08 & 2 & 0,16 & 3 & 0,24 \\
\hline Lokasi perusahaan kurang dapat dijangkau & 0,04 & - & & - & \\
\hline Barang yang dijual kurang berkualitas & 0.02 & 1 & 0,02 & 4 & 0,08 \\
\hline Total & & & 5,94 & & 5,11 \\
\hline
\end{tabular}

Berdasarkan analisa melalui matriks QSPM di atas maka dapat diketahui bahwa PT. Galleon Cahaya Investama perlu melakukan pengembangan pasar supaya dapat berhasil dalam melakukan persaingan dengan kompetitor lainnya.

\section{KESIMPULAN}

a. PT.Galleon Cahaya Investama harus dapat memanfaatkan peluang dengan menggunakan strategi pengembangan pasar.

b. PT. Galleon Cahaya Investama dapat melakukan grow and build strategy. Strategi ini digunakan dengan melakukan pengembangan pasar terutama dengan memanfaatkan secara maksimal kekuatan yang dimiliki

Strategi pengembangan pasar yang didapat ini tepat digunakan bagi perusahaan yang memiliki peluang untuk berkembang. Seperti penelitian terdahulu (Lu, 2017) dimana dalam penelitian mereka juga dapat dilihat bahwa perusahaan yang diteliti disarankan untuk melakukan pengembangan pasar. 


\section{DAFTAR PUSTAKA}

David, Fred R. (2013). Strategic Management: Concepts and Cases (14 ${ }^{\text {th }}$ ed.). Harlow, England : Pearson Education Limited.

Friedrichsen, Mike., Zarea, Hadi., Tayebi, Amin., Abad, Fatemeh Asadi Saeed. (2017). Competitive Strategies of Knowledge and Innovation Commercialization: A Unified SWOT and Fuzzy AHP Approach. AD-Minister, 3 (30), 45-72.

Hossain, Khandakar Akhter., Zakaria, N.M. Golam, Sarkar, M.A.R. (2017). SWOT Analysis of China Shipbuilding Industry by Third Eyes. Procedia Engineering, 194, 241-246.

Koupaei, Sobhanallahi, Horri. (2015). A Fuzzy ANP-SWOT Approach for Analayzing the IT Problems based on capabilities in Iran.International Journal of Supply and Operations Management, 1 (4), 427-438.

Lu, Lung Tan. (2017). Strategic Planning for Xiaomi: Smart Phones, Crisis, Turning Point. International Business Research, 10(8), 149-160.

Neelesh, Kushwah, R.K. (2018). A Study of Importance for Analyzing and Understanding the Firm's External Environment in Delhi. Journal of Advances and Scholarly Researches in Allied Education, 14 (2), 471-475.

Pazouki, M., Jozi, S.A., Ziari, Y.A. (2017). Strategic Management in Urban Environment Using SWOT and QSPM Model. Global J. Environ. Sci. Manage, 3(2), 207-216.

Pearce, Robinson. (2016). Strategic Management: Planning for Domestic and Global Competition. (14 ${ }^{\text {th }}$ ed). New York, United States of America: Mc Graw-Hill Education.

Satpayeva, Zaira Tulegenovna. (2017). State and Prospects of Development of Kazakhstan Innovative Infrastructure. European Research Studies Journal, 20 (2B), 123-148.

The World Bank. (2018). Indonesia Economic Quarterly, Retrieved June, 2018, from Worldbank website.

https://www.worldbank.org/en/country/indonesia/publication/june-2018-indonesiaeconomic-quarterly 
